\title{
Literacy and technologies in EFL settings: Fostering reading comprehension on the Internet
}

\author{
Carolina Girón-García \\ Universitat Jaume I, Castellón de la Plana, Spain
}

Article received 23 February 2015, accepted 15 March 2015, final version 8 June 2015 DOI: http://dx.doi.org/10.5565/rev/jtl3.616

\begin{abstract}
In a period of dramatic technological change (Kellner, 2000) Information and Communication Technologies (ICTs) are developing exponentially and this has inevitably had an impact on how learning and literacy in the $21 \mathrm{st}$ century are being redefined (Benson \& Chik, 2010). For this reason, educators have the need and the responsibility to adapt and integrate the curricula into a new digital context (Schmar-Dobler, 2003), making use of available digital tools in order to ensure that education is relevant to the demands of today's society (Kress, 2003; Luzón, 2002). This article highlights the role of digital literacy to foster reading comprehension on the Internet in order to solve problems, activities, tasks; or simply to satisfy learners' needs by providing an overview of one pedagogical intervention and qualitative data that shows its successful implementation.
\end{abstract}

Keywords: New literacies, Spontaneous New Literacies, technology, TEFL, Cybertask

\section{Resumen}

En un época de cambios tecnológicos dramáticos (Kellner, 2000), las Tecnologías de la Comunicación y Información (TIC) se están desarrollando de manera exponencial. Inevitablemente, esto ha tenido un impacto en cómo se están redefiniendo los conceptos del aprendizaje y de la alfabetización en el siglo 21 (Benson \& Chik, 2010). Por esta razón, los educadores tienen la necesidad y la responsabilidad de adaptar e integrar sus planes de estudio en un nuevo contexto digital (Schmar-Dobler, 2003), haciendo uso de las herramientas digitales disponibles a fin 
de garantizar que la educación sea pertinente a las demandas de la sociedad actual (Kress, 2003; Luzón, 2002). Este artículo pone de relieve el papel de la alfabetización digital para fomentar la comprensión de la lectura en Internet con el fin de resolver problemas, completear actividades y tareas; o simplemente para satisfacer las necesidades de los alumnos. El artículo proporciona una visión general de una intervención pedagógica y delinea datos cualitativos que muestra su implementación exitosa.

Palabras clave: Nuevas alfabetizaciones, nueva alfabetizaciones espontáneas, la tecnología, la didáctica de la lengua inglesa como lengua extranjera, Ciber-tareas

\section{Resum}

En un època de canvis tecnològics dramàtics (Kellner, 2000), les Tecnologies de la Comunicació i Informació (TIC) s'estan desenvolupant de manera exponencial. Inevitablement, això ha tingut un impacte en com s'estan redefinint els conceptes de l'aprenentatge i de l'alfabetització al segle 21 (Benson \& Chik, 2010). Per aquesta raó, els educadors tenen la necessitat i la responsabilitat d'adaptar i integrar els seus plans d'estudi en un nou context digital (Schmar-Dobler, 2003), fent ús de les eines digitals disponibles a fi de garantir que l'educació sigui pertinent a les demandes de la societat actual (Kress, 2003; Luzón, 2002). Aquest article posa en relleu el paper de l'alfabetització digital per fomentar la comprensió de la lectura a Internet per tal de resoldre problemes, completear activitats i tasques; o simplement per satisfer les necessitats dels alumnes. L'article proporciona una visió general d'una intervenció pedagògica i delinea dades qualitatives que mostra la seva implementació reeixida.

Paraules clau: Noves alfabetitzacions, nova alfabetitzacions espontànies, la tecnologia, la didàctica de la llengua anglesa com a llengua estrangera, Ciber-tasques 


\section{Introduction}

Entering into the new millennium, as educators in the EFL field, we have had to adapt to many new technological advances. The revolution in the media context has entailed changes in the teachinglearning field (AACTE \& P21, 2010), and has also provoked changes in the university curricula design. Furthermore, the way people read and write has been altered due to dramatic changes in methodologies being carried out. As educators, we have had to reshape our curricula designs in order to make them more appealing and productive for university students, and rethink new ways to implement the contents in the EFL classroom so that they reflect these technological advances. But perhaps we should ask ourselves the following question: "How can educators understand and deal with these issues?" Probably, the first step is getting to know what it means to be literate nowadays.

This article describes a pedagogical implication, based on a WebQuest-based model ${ }^{1}$ activity, designed to be implemented and completed as a complementary activity in a subject entitled 'English Applied Linguistics: An Introduction', at university level (implemented at 'Universitat Jaume I', Spain). Despite the fact that Webquests are not a 'new' pedagogical intervention (they were first introduced in two decades ago), it can be argued that they have not been fully exploited in university classes, in part due to a lack of conceptual knowledge of how to best implement it Recent studies show that it is not yet possible to claim that technology has been fully

Bellaterra Journal of Teaching \& Learning Language \& Literature. 8.2 (May-June 2015) ISSN 2013-6196 
integrated into language teaching, despite the many advances made thus far (BECTA, 2008; Dooly, 2009). This study outlines a case study of a successful execution of a Webquest-inspired teaching activity. Following a detailed description of the pedagogical intervention, the authors introduce qualitative data taken from two case studies of students' final output, obtained during the implementation of the teaching process.

\section{The concept of 'Literacy'}

The concept of 'literacy' has encountered multiple problems, since it can be related to several disciplines (i.e. music, images) and as a result, different terminologies should be used in this respect. Thus, this term has been an object of controversy among researchers and for this reason, several principles have been considered in order to define what it is to be literate. Kern (2000, pp.16-17) emphasizes the following premises as a basis for a definition: (1) interpretation, (2) collaboration, (3) conventions, (4) cultural knowledge, (5) problemsolving, (6) reflection and self-reflection, and (7) language use. But these seven principles can be summarized by highlighting that literacy involves communication. When students practice literacy in a nonnative language, they learn about vocabulary, grammar and discourse; but they are also learning new ways to structure their thoughts.

This is underscored by Kress (2003), who argues that the concept of 'Literacy' can be understood from two different dimensions: linguistic and cognitive. From a linguistic perspective, the 
term 'Literacy' has to do with how people use the language, and more specifically, how they use the written language. In contrast, from a cognitive perspective, reading demands active participation at a cognitive level. That means that reading is a thinking process through which readers must relate the written symbols they perceive to their knowledge of language, of texts, of content areas, and of the world, in order to bring meaning to a text.

These two dimensions (linguistic and cognitive) are relevant as far as printed literacy is concerned (more traditional perspectives on literacy predominant up to the 1970s), but we might also highlight digital literacy for the purpose of our present work.

The appearance of computers with networked information (Internet) has provoked changes in literacy, resulting in the screen as the main source of communication in many occasions. Thus, the union of reading and technology, on the one hand, and the Internet, on the other hand, has created a new form of literacy (Schmar-Dobler, 2003). For some time now, theorists and academics have been calling for more recognition of the multiple literacy requirements of today's students; they must now learn how to use technological resources, as well as being able to surf the Web, use e-mail, and evaluate relevant information (cf. Kress \& van Leeuwen, 2001; Thorne, Black and Sykes, 2009; Dooly, 2014).

In Kress' words (2003), literacy may include the reading of all kinds of semiotic and meaning loaded forms. Furthermore, the author explains that in the last few decades, the "image" has become 
dominant over the "writing", and this conversion has been accompanied by a "move from the dominance of the medium of the book to the dominance of the medium of the screen" (p. 1). Along this line, it can be argued that it is important to make a three-fold distinction between (1) 'New Literacies', (2) 'Spontaneous New Literacies', and (3) 'New Technology Skills' (Girón-García, 2013, p. 141-142). 'New Literacy' can be defined as a new way of reading on the Web. Traditionally, people used to read on paper format (books, articles, newspapers), but with the arrival of the Internet in the 20th century, a new way of reading appeared (digital texts). In contrast to this idea, we suggest the notion of 'Spontaneous New Literacy' which implies surfing the net in order to gather information but with the specific feature of not having received any previous learning or background information. The last term we consider worth mentioning here is the idea of 'New Technology Skills', which we define as the knowledge and ability to use and combine Internet resources in order to solve problems, activities, and tasks, or simply to satisfy needs.

It is therefore of paramount importance to make a clear distinction between characteristics concerning (a) Traditional Texts and the (b) World Wide Web (WWW) (Girón-García, 2013, p.143). In traditional texts, print remains static as the information they contain do not change each time a book is opened. Print format is also linear, as it follows the intended path of the author, and it is usually sequential, as it may follow a particular order or ranking (Coiro, 2003). Furthermore, they contain graphics that consist of static images

Bellaterra Journal of Teaching \& Learning Language \& Literature. 8.2 (May-June 2015) ISSN 2013-6196 
(Sutherland-Smith, 2002). In contrast to traditional texts, in digital texts (World Wide Web), the information is constantly changing, as it is frequently revised, removed, or rearranged (Schmar-Dobler, 2003).

These new formats feature non-linear hypertexts that allow readers to navigate their own course - by selecting links in a variety of orders - that may be different from the intended path of the author or other readers (Coiro, 2003). In addition, new formats are also typically non-sequential, as readers can jump from one place to another (Sutherland-Smith, 2002). Finally, in digital texts, graphics on the Web appear more lifelike than in conventional texts, since multiplemedia images can integrate a variety of symbols and multimedia formats, such as icons, photographs, animated symbols, cartoons, advertisements, audio and visual video clips, and virtual reality environments (Coiro, 2003).

It is important to bear in mind that although books and writing are, in many ways, being replaced by other forms of texts; these 'traditional' formats must still be taken into account because they offer something unique that cannot be replaced by the screen, music, images, and soundtracks. But with the advent of the Internet, we think it is of paramount importance to develop content-based materials in this new digital environment for the university curricula in order to help students understand this cyber genre. Accordingly, we deem it necessary to focus on this new digital environment (Internet) as a new tool for reading in EFL settings. 


\section{The Internet as a new tool for reading}

Electronic texts are a fairly new medium for reading and informationgathering for teachers and students. Information-gathering through electronic or digital means requires a specific type of literacy (knowing where to look, using hyperlinks, application of critical thinking) which is especially important for facing activities or tasks related to the Web. Accordingly, searching for information on the Web might be confusing sometimes because traditionally we are used to extracting information from printed versions (Coiro, 2003). It has been reported that students interacting with digital texts "perceive Web text reading as different from print text reading" (SutherlandSmith, 2002, p. 664). As a consequence, students may have feelings of frustration and stress due to unsuccessful search of information. This is further evidence of the need for both teachers and students to have both multiple literacy competencies in order to be prepared for their future as $21^{\text {st }}$ century citizens (Dooly, 2014; Herrera, 2012). For this reason, as educators we need to foster new literacies in the classroom and foster reading comprehension on the Internet among our university students.

From the teacher-researcher's point of view, what we intend is: (1) to provide instructional solutions to foster new literacies in the classroom; (2) to provide instructional solutions to foster reading comprehension on the Internet (3) to test the efficiency of the instructional approach. If we want that students become proficient in all the skills related to multiple literacies, they need to receive 
instruction from teachers. For this reason, what teachers really need to do is give instruction and training in various literacy-based technologies. We proposed that the Internet, for instance, could be the most predominant medium where both teachers and students can share a common ground; thus, a central axis for language teachers must be learning how to integrate the Internet effectively in literacy instruction. Following on these ideas, we think that the new technologies in combination with the new literacies might offer a valuable support in students' reading development if (as teachers) we provide them with all the necessary tools.

Some of the better known tools to implement literacy instruction with the use of the Internet are electronic books and online texts. In fact, electronic books (e-books) offer an appealing and visual environment for the student and have several advantages such as being modifiable in order to meet the needs of the reader (Anderson-Inman $\&$ Horney, 1997). These can be further supported by a wide variety of other reading materials that are available on the Web (books, newspapers, magazines, etc.). In addition, research carried out on these issues indicates that online reading has positive effects on student comprehension of digital texts and learning in general (Anderson-Inman \& Horney, 1997; Anderson-Inman, Horney, Chen, $\&$ Lewis, 1994). Moreover, the use of the Internet for reading in order to improve the general ability for student comprehension of texts can be directly related to students' personal needs and interests, thus promoting a more autonomous student role and sense of control over 
their own work that might result in a higher degree of motivation. Nevertheless, it is not simply a question of the tool being put to use. It is necessary to also consider how these tools are used (pedagogical design). Thus, we now turn our attention to another aspect of this study, which is task-based learning activities, also known as 'Cybertasks'.

\section{Task-based learning activities: 'Cybertasks'}

It is the authors' perspective that working with on-line task-based activities (Cybertasks) will optimally involve mutually reciprocal active participation, where both teachers and students learn media literacy skills and competencies. Thus, we will outline the design of a Cybertask which helps in the students' development of an autonomizing reading competence (Villanueva, Luzón \& RuizMadrid, 2008).

In our context, a task-based learning activity is designed to engage students in searching information through the Internet in order to collect, use and transform information concerning the field of 'Applied Linguistics'. In fact, this kind of task-based activity may help students to: (a) develop their metacognitive skills in order to learn how to guide their learning on their own (Luzón, 2002), and (b) use the Internet as a tool for their personal learning plan.

This Cybertask consists of a WebQuest-based model activity to be implemented and completed as a complementary activity ('Written Assignment') to be given towards the end of the semester in the 
subject 'English Applied Linguistics: An Introduction' (EA0914). We first present the Cybertask and the objectives anticipated for each of the activities.

(Q1): How would you define Applied Linguistics? (Use your own words). This question tries to highlight the following features:

- Use of information: knowing how to use specific language concepts and expressions (in English).

- Information search: the ability to identify information in different texts, and find common traits in the information found on the Web.

- Information organization: this refers to coherence and cohesion. Coherence is adequacy of the text and semantic consistency; whereas cohesion is refers to textual organizers used to cohere a text (between lines, sentences and paragraphs).

- Content: relevancy of the answer to the question. Information relevance is important when students select ideas from the Web pages provided.

(Q2): Which of the branches of Applied Linguistics do you find more interesting? Justify your answer. This question aims to highlight the following features:

- Use of information: relevance regarding specific language terminology in English. 
- Information search: identifying and finding common features in the information provided in the different Web pages offered is very important to answer this question.

- Content: relevance of information employed regarding this question is important to attain an excellent score.

(Q3): Which of the three approaches (Environmentalist Approach, Nativist Approach, and Interactionist Approach) to language learning do you disagree with? Why? Justify your answer. This question bears in mind the following features:

- Use of information: use of specific language concepts and expressions (in English).

- Information search: identifying information in different texts, and finding common traits in the information found on the Web.

- Information organization: coherence and cohesion. Coherence is adequacy of the text and semantic consistency; cohesion consists of the textual organizers to cohere a text (between lines, sentences and paragraphs).

- Content: information relevance is important when students select ideas from the Web pages provided.

(Q4): Create your own PowerPoint with only four slides where you will have to summarize how each dimension (Contrastive Analysis, Error Analysis, Performance Analysis, and Discourse Analysis) is 
understood in Second Language Learning (SLL) contexts. This question considers the following features:

- Content: students are expected to provide relevant information to answer this question and get an excellent result.

- Creativity: being creative is a very important feature to bear in mind, since students are expected to create their own PowerPoint presentation summarizing each one of the dimensions mentioned for the purpose of answering this question.

- Information organization: students should consider coherence and cohesion; not only between paragraphs, lines, and sentences; but also between the slides employed for their presentation design.

- Presentation: students' presentation should be clear and concise, bearing in mind key concepts and short sentences for their further development.

(Q5): You are an English teacher and you have to create a reading activity for two different types of students: (1) Middle school students (12 years old) and (2) High school students (17 years old). The topic for the reading is "Christmas". Justify the design of the activity bearing in mind the age and motivation factors. This question highlights the following features:

Bellaterra Journal of Teaching \& Learning Language \& Literature. 8.2 (May-June 2015) ISSN 2013-6196 
- Vocabulary and grammar: students are expected to employ the adequate vocabulary around the topic "Christmas", and correct grammar use for the purpose of this activity.

- The presentation is of paramount importance for this activity, because students should adapt the design of the activity considering the 'age' and 'motivation' factors, with regards to the objectives of the activity.

(Q6): You are an English teacher and one of your colleagues has a problem and cannot teach on Friday. He asks you to develop a listening activity for a very special group: since 10 out of 20 students enrolled are very visual and the other 10 students are verbal, how would you cope with this diversity when designing materials? This question focuses on the following features:

- Creativity: a crucial feature when designing materials for students with different profiles.

- Presentation of contents: should be adapted and understandable, considering the students' diversity (in terms of learning profiles).

- Vocabulary and grammar: should be taken into consideration when designing materials for students.

(Q7) Final Activity: Write a short report about the following questions in your own language (Spanish or Catalan).

(Q7.1): How long have you been working on this activity?

Bellaterra Journal of Teaching \& Learning Language \& Literature. 8.2 (May-June 2015) ISSN 2013-6196 
(Q7.2): Did you find it interesting? Why?

(Q7.3): How do you think this task is related to the objectives of the program?

(Q7.4): Do you think this task has helped you to face the final exam' Why? These questions specifically aims to engage students' interests and motivation. This activity is expected to expand students' interest and motivation in regards to every single activity proposed in this Cybertask. Motivation is a very important factor to bear in mind if we want our students to engage in a particular task. Learners need to feel motivated in order to keep their attention, not only in the university setting, but also outside the classroom. For this reason, we propose this Cybertask to university students because it provides them a topic of interest: 'English Applied Linguistics: An Introduction' (which corresponds to one of the subjects of the English Studies degree).

We need to highlight the fact that students' attention by means of a Cybertask ensures that they are working on a topic they are interested in. Accordingly, students' answers to this final activity provides valuable information concerning: (1) students' improvement in their learning process through improved performance and involvement in each single activity in the Cybertask, and (2) the role of WebQuest and online materials.

Figure 1 shows the 'front page' or 'home' page of the digital version of the Cybertask (adapted from Girón-García \& Ruiz-Madrid, 2013 , p. 5-11) as it is presented to the students.

Bellaterra Journal of Teaching \& Learning Language \& Literature. 8.2 (May-June 2015) ISSN 2013-6196 


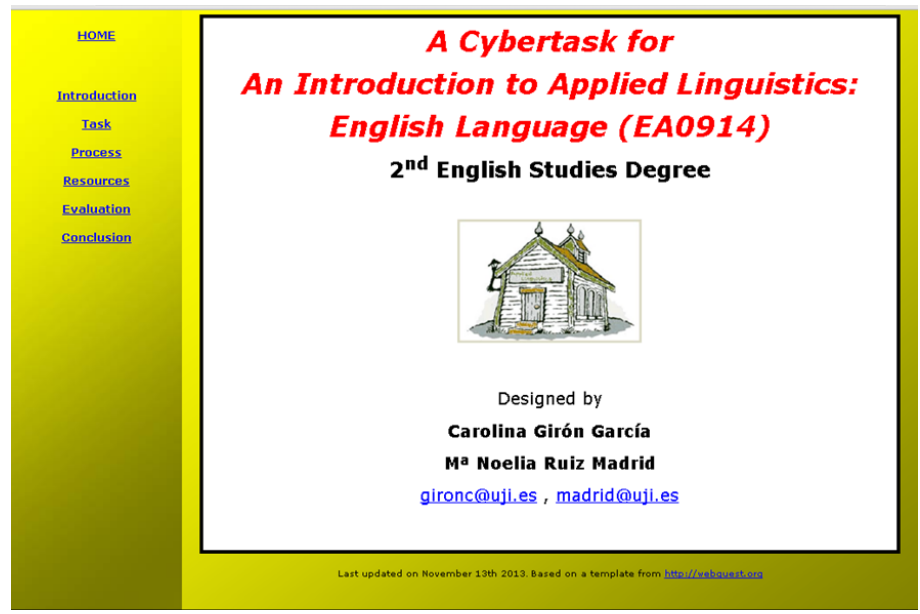

Fig. 1. Front page of the Cypertask

The home page leads to an introduction of the pedagogical framework in which the premises of the 'Webquest based model activity' are explained to the students and how it will serve the students to gain more knowledge in the content matter.

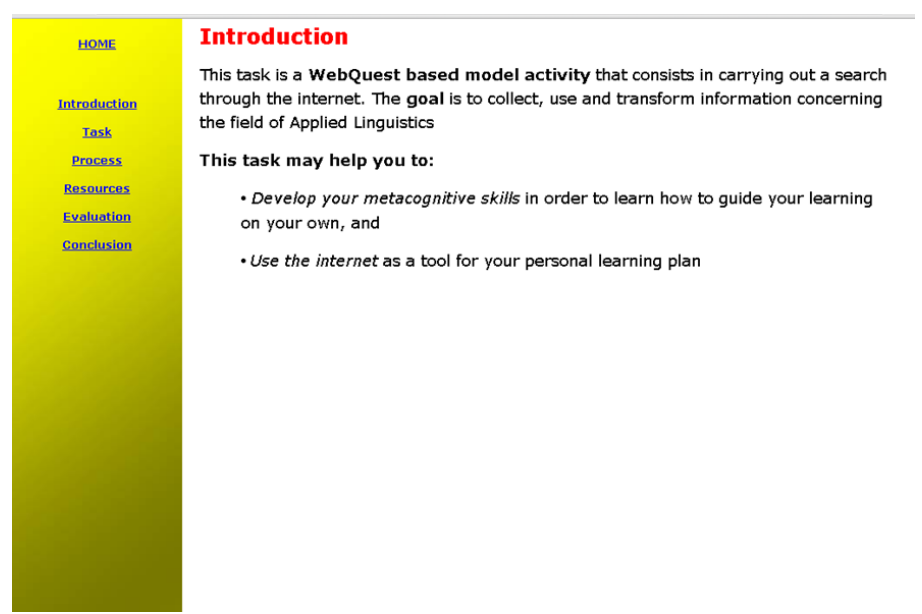

Fig. 2. Introduction

Figure 3 shows the design and presentation of one of the tasks the students are asked to complete. It provides an outline of expected learning objectives, the driving questions and supporting resources.

Bellaterra Journal of Teaching \& Learning Language \& Literature. 8.2 (May-June 2015) ISSN 2013-6196 


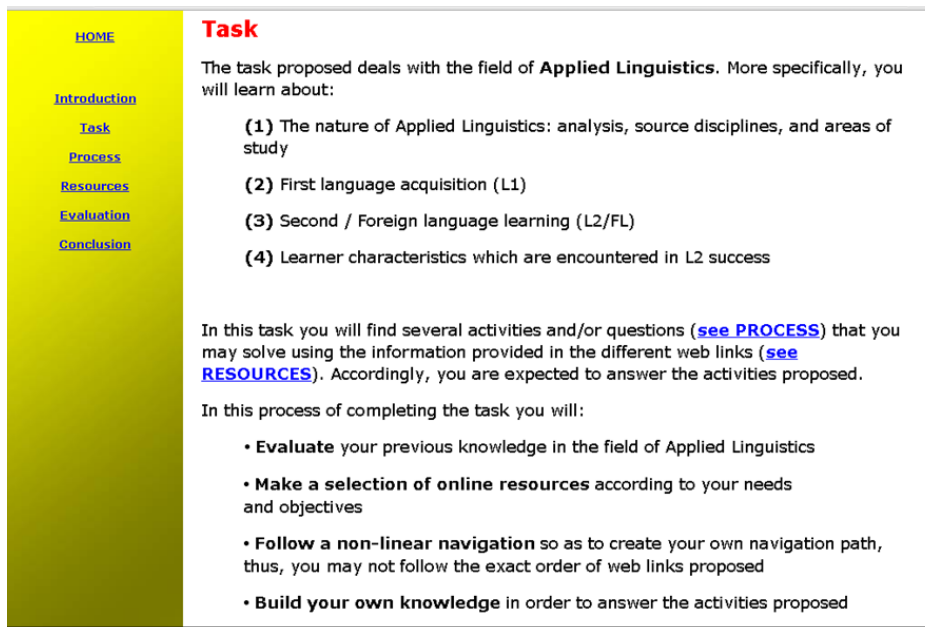

Fig. 3. Task design

In the task design, a link is provided to the 'process' (figure 4) which provides more detailed instructions on what the students should do to accomplish this part of the activity.

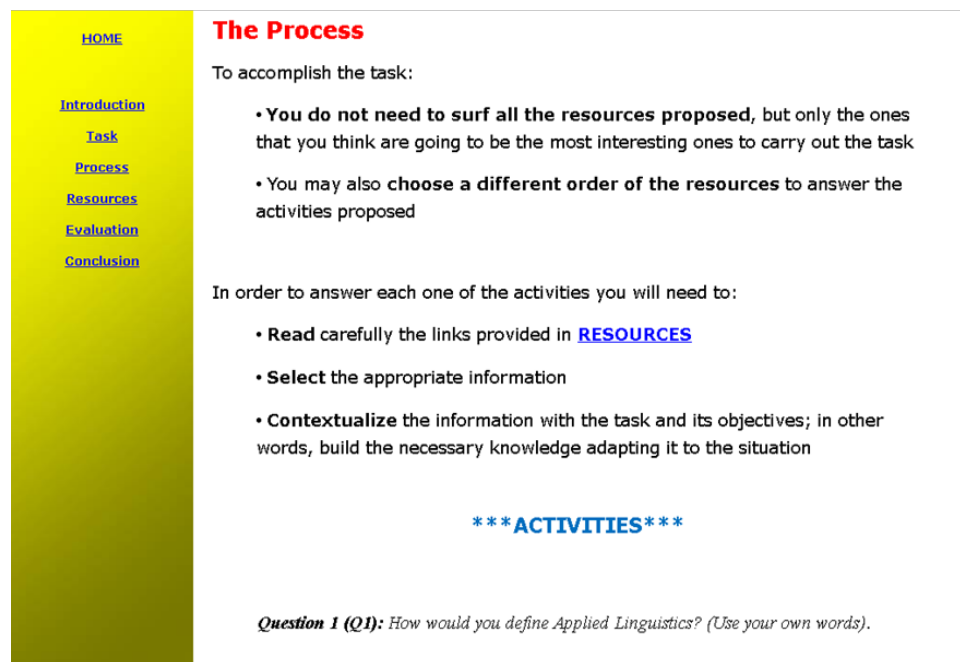

Fig. 4. Process description

This, in turn, is broken down into detailed activities (figure 5).

Bellaterra Journal of Teaching \& Learning Language \& Literature. 8.2 (May-June 2015) ISSN 2013-6196 


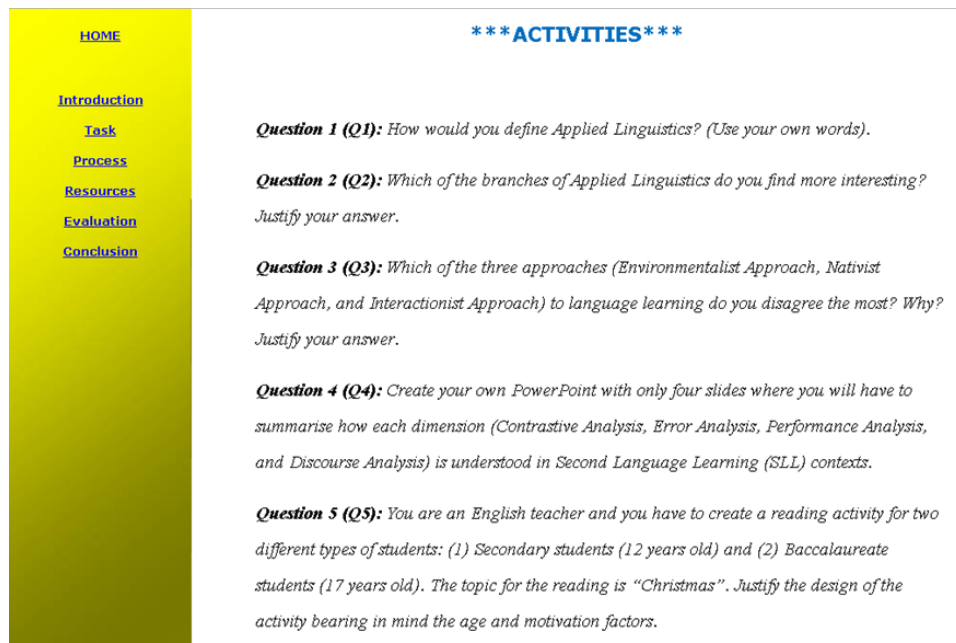

Fig. 5. Activity description

The provision of suitable resources is key to the successful execution of the tasks. Figures 6 and 7 show how direct resources are given to the students according to task or for more general information.

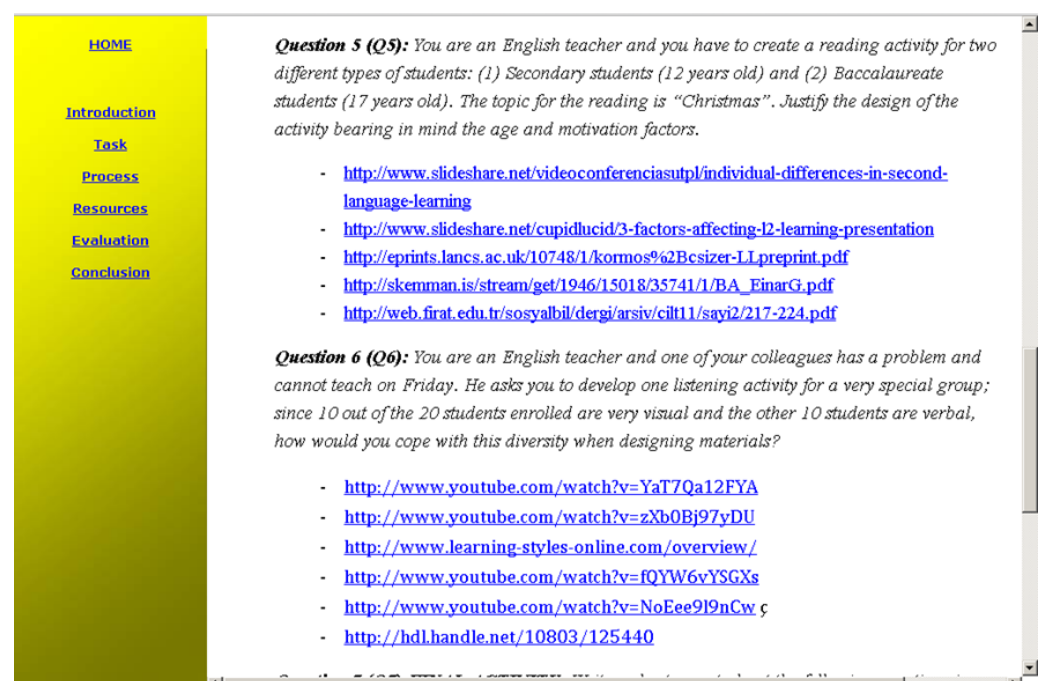

Fig. 6. Resources list for a specific task 


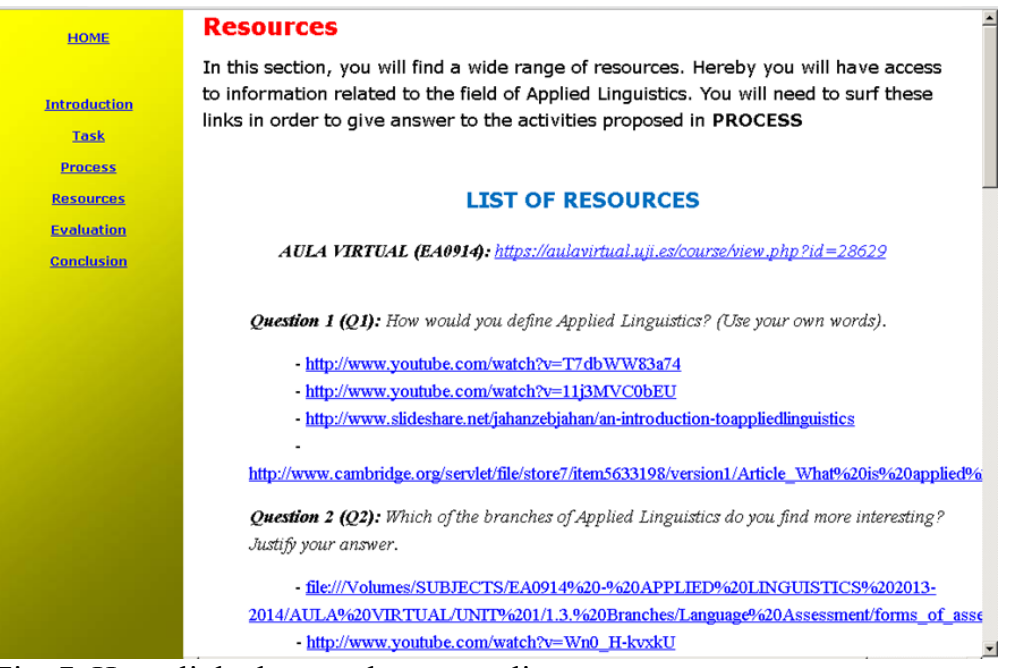

Fig. 7. Hyperlinked general resource list

Students are also provided with an example of how their work will be assessed. This is carried out through an evaluation rubric as shown in figure 8 .
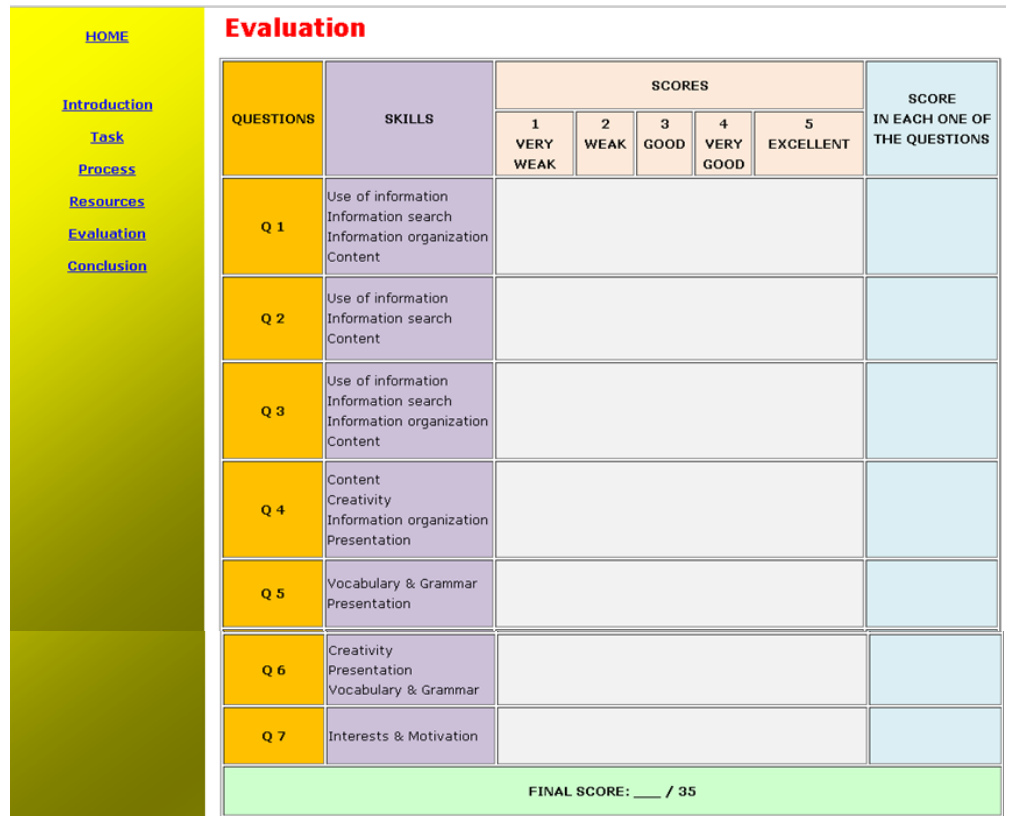

Fig. 8. Rubric

Bellaterra Journal of Teaching \& Learning Language \& Literature. 8.2 (May-June 2015) ISSN 2013-6196 
Once students have completed this Cybertask, they are able to reflect on their knowledge with the development of the new technologies (ICTs) in order to learn and/or acquire some information in relation to the field of Applied Linguistics.

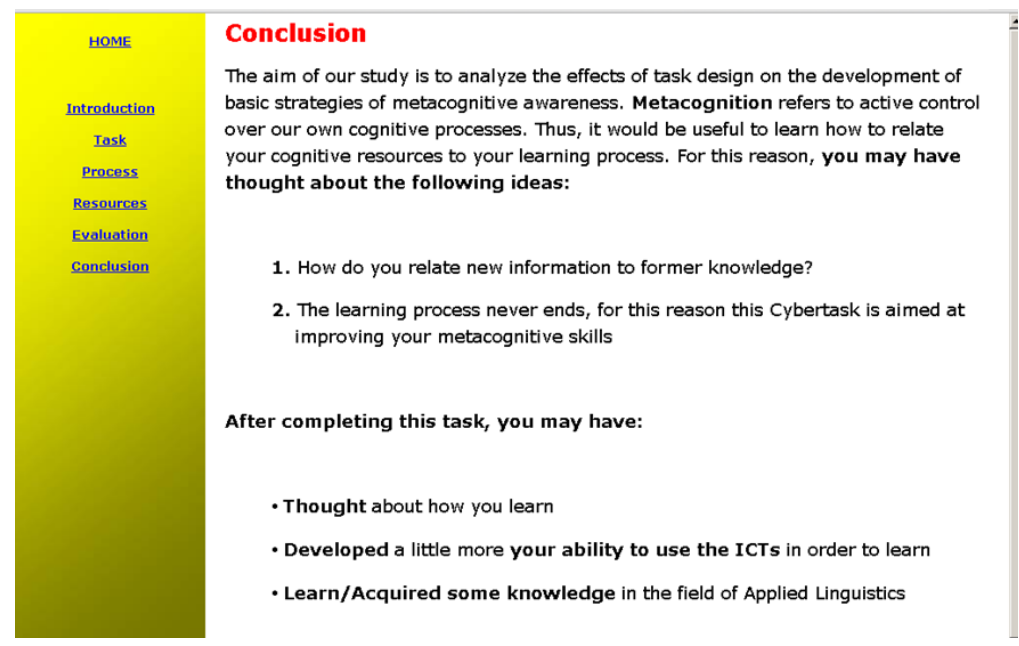

Fig. 9. Promoting student reflection

\section{Data Compilation: Context of Implementation}

The Cybertask entitled 'English Applied Linguistics: An Introduction' (EA0914) was carried out over the course of several days, depending on the needs of every student. The Cybertask consisted of seven activities which were completed by a total number of 58 participants selected from the group taking the subject 'English Applied Linguistics: An Introduction' (EA0914) in the 2nd year course of the English Studies degree at the Universitat Jaume I (Spain). Among these 58 students, two were selected for the purpose of case studies.

The study took place in the first semester (SeptemberDecember) of the 2014-2015 academic years and students' 
participation was one of the compulsory written assignments and represented one point added to the final mark at the end of the semester.

Students were required to submit their Cybertasks to a 'Moodle' platform called 'Aula Virtual' (i.e. Virtual Classroom), so the teacher-researchers had access to all their task output. The two foci for our study has been the 'Cybertask English Applied Linguistics: An Introduction' and the 'Final Exam' mark for data collection. Two students have been selected to examine in detail their reflections in order to observe whether the Cybertask supported the students' development of multiple literacies associated with the $21^{\text {st }}$ century competencies. The students were selected as representing excellent work (Student 1, received a 10 out of 10 in the final activity) and average work (Student 2, received a 6,5 out of 10 in the final activity).

\section{Data Analysis: Students' Perspectives}

'STUDENT 1': Exam Result: 10 points (out of 10 points)

The following excerpts stem from Student 1's answer to the activity (Write a short report about the following questions in your own language (Spanish or Catalan). This activity was further prompted by the questions:

(Q7.1): How long have you been working on this activity?

(Q7.2): Did you find it interesting? Why?

(Q7.3): How do you think this task is related to the objectives of the program?

Bellaterra Journal of Teaching \& Learning Language \& Literature. 8.2 (May-June 2015) ISSN 2013-6196 
(Q7.4): Do you think this task has helped you to face the final exam' Why?

\section{Excerpt 1}

This Cybertasks work has taken me about a week, since the search for information and sees the proposed videos have led me some time. In my opinion, has been a different and less expensive to make work than the previous ones, because it is related to concepts that we have given in class. However, having the tests closely, I've had to reduce my time in this to devote it to the study of the subjects, and the truth is that I would like to further develop the questions.

Student 1 indicates that while the activity was somewhat timeconsuming (the student has dedicated a week and felt that this was insufficient), at the same time, it was innovative and worthwhile (different and less expensive [sic]). In addition, the student would have dedicated more time if it had been possible, however the need to move on to the final exam was seen as a time constraint. From the perspective of task design, these comments can be interpreted as indicators of a high level of motivation-building although the timing did prove a bit problematic.

\section{Excerpt 2}

On the other hand, I think that it has been a different and more interactive; work since we have removed sources provided information to then apply it in the exercises. And of course, we had to use our minds to develop certain responses with our words.

In addition, it has allowed me to take a look at the books and articles of the links, and honestly, I think that I will be very useful in my studies; as well as suggested videos, which I have 
seemed concise and easy to follow, even some with funny and animated touches.

Student 1 again highlights the sense of innovation in this type of approach to the content and values the availability of different resources. The pedagogical design allowed the student more autonomy and supported reflection and application of the content provided through the resources. The student also valued the accessibility of the resources as well as the fact that they were at times "funny and animated". This corroborates the argument that Webquests promote student autonomy and help bridge the gap between theory and practice.

\section{Excerpt 3}

As for the relationship with the objectives of the programme, I think that prepare works (in general, in all subjects) is something that is necessary for our academic performance, and this in particular provides the ability to relate the concepts given in class, as well as to reason critically the information that has been suggested to us. In addition, it also helps us to work relatively independently, learning at the same time.

Once more, Student 1 focuses on the opportunity of applying content knowledge, the think critically and the need for learner autonomy.

\section{Excerpt 4}

From my point of view, the work brings together the terms and major theories of all issues, and most importantly, resumes them, something that is very helpful for the exam of Linguistics. However, this means leaving aside the specifics of each item, because you have to adhere to the general. Even so, it has been a good way to "Refresh" the information we had stored for months in our head. 
In the final excerpt, the student places emphasis on the fact that the activity has helped the learners to review all the content, which was particularly useful for the final exam. The student also points out that the activity helped the learners to synthesize the course content.

'STUDENT 2': Exam Result: 6.5 points (out of 10 points)

As with Student 1, the following excerpts stem from Student 2's answer to the report-writing activity, prompted by the same questions.

\section{Excerpt 5}

First of all, I can say have employed around two and a half days to complete this activity, because despite all the materials needed to make the task, these were a considerable extension and required to be read with some care. However, I do not think that it has been too long nor that that time has been lost, because I think that it has helped me to review concepts that time ago I studied, and that in fact, now I know that I needed to review. And this is the reason why this task found me interesting, since it has given me the opportunity to dig a little deeper into concepts that had previously studied, and not only that, but also to understand them in a clearer way.

Student 2 also emphasizes the fact that this activity required considerable time, although the student applied less time to the task than Student 1. Similar to Student 1, Student 2 is careful to highlight that $\mathrm{s} /$ he does not feel that the time required was a waste; the activity has proven useful for review of subject matter and for a deeper understanding of the concepts already looked at during the course.

\section{Excerpt 6}

Bellaterra Journal of Teaching \& Learning Language \& Literature. 8.2 (May-June 2015) ISSN 2013-6196 
In second place, after having used the materials of the subject, along with the sources provided in the virtual task, can assure with relative certainty that, indeed, this task is directly related to the objectives of the programme, since it gets students to develop skills such as writing, and the critical sense, while it is "forced" to review the contents of the subject and to put them into practice, skill that seems to be fairly important within the field that concerns us, applied linguistics.

Student 2 discusses the transparency of the activities and the objectives (they are clearly linked for the learners) and how the activity has helped the learners develop writing skills which are important for them in their field of applied linguistics.

\section{Excerpt 7}

Finally, I think that this task I can be helpful to deal with the final examination of the subject, because, while it does not include each and every one of the concepts seen in class, - as expected, given the length of the task, in this case, yes addresses some of the most notorious and even encouraged to read those that do not appear explicitly, but which nonetheless are related to those that do appear.

In conclusion, from my point of view, this is a very interesting and desirable task for students. It involves some of the terms and concepts of increasing importance of the subject and encourages the development of these concepts by students, two very important things to deal with the final exam.

Similar to Student 1, this student underscores the usefulness of the Cybertask for reviewing and preparing for the final exam, while providing the possibility of going further into related concepts. 


\section{Discussion of the study results}

The qualitative analysis of the responses from these two students allows us to discover a network of strategies, behaviours and emotional, cultural and cognitive trends that offer a different perspective in the study of the learning profiles concerning the use of ICT's as a learning resource (Navarro, Luzón \& Villanueva, 1997).

From the students' responses it can be deduced that, through their engagement with the Cybertask 'English Applied Linguistics: An Introduction' (EA0914), the students do apply key $21^{\text {st }}$ century competences. Both students mention their ample use of varied resources, indicating 1) their ability to deal with learning processes by means of managing different sources of information and selecting information. They are also able to 2) synthesize and take decisions about the use of that information and to build new knowledge in the process of answering the different activities. Both students show that they can 3) reflect through a coherent discourse, bearing in mind the process and not only the result of the task. They 4) employ language correctly with regards to grammar and lexicon, and clearly 5) understand the texts and answer the activities proposed.

These findings have pedagogical implications for teachers. We should bear in mind that students in general, and more specifically university students, demand the use of the new technologies not only to receive instruction in the classroom, but also as a means to learn languages and content. In fact, their interests in interactive tools and the Internet also suggest the need to teach online reading from a 
critical point of view, since they are often 'uncritical' consumers of online content. This implies that students not only have to know how to read from a computer screen, they need to develop the ability to comprehend and be able to interpret that information according to their previous knowledge; in short, they must become critically discerning members (Dooly, 2014) of the 'Net Generation' (Tapscott, 1998).

As regards the instructional implications of literacy instruction, these results support the proposals posed by Morgan (1997; based on previous work by Tierney \& Shanahan, 1991). Morgan suggests that teachers must look for different ways to integrate reading as often as possible so as to lead to students' comprehension and retention of the content of a certain subject. Teachers should also ensure that students have the adequate background information related to the content they are going to face (Alexander \& Jetton, 2000) and provide instruction on the appropriate vocabulary in order that students reading comprehension is more effective. As a result, their critical thinking awareness about different kinds of printed and online texts can be better developed. The results also support the premise that online instruction should motivate students to search and explore different websites depending on their educational needs; and encourage multiple readings in relation to a certain subject-matter from different perspectives in order to develop and promote their reading skills on the Internet. 
Finally, we believe that from the educators' point of view, the development of online task-based activities (also called 'Cybertasks', Girón García, 2013) can be used to introduce new genres in instructional settings. These Cybertasks as new task genres point towards a new direction for teaching in the new literacies.

\section{Conclusions}

The aim of the present work focuses on discussing the integration of literacy and the use of technologies in order to foster reading comprehension on the Internet in EFL settings. Along these lines, we stress the importance of helping students to use the Internet to solve problems, activities and tasks in order to better meet their individual learning needs. Additionally, when dealing with a foreign language, Cybertasks can serve as a key means of getting students to experiment with the target language within a pedagogical framework that places the "teacher as a helper, an ally who gives them advice" (GirónGarcía, 2013, p. 432).

In our work we have discussed that teaching and learning are related to information literacy and technological skills as key issues in contemporary society. We refer to technological skills such as knowing how to select, organize and use information in order to solve problems and handle new situations, since we strongly believe that knowing how to manage the Web in content-based learning will facilitate life-long learning; in fact, they are considered as the basic competencies needed for continuous and autonomous learning. 
In the light of the result of the present study, we argue that the results of the Cybertasks served as a complement to the face-to-face teaching activities and materials in way that encouraged continuous and autonomous learning on the part of the students of the subject 'English Applied Linguistics: An Introduction' (EA0914). Furthermore, we believe that these kind of online activities favoured the students' learning processes outside the classroom.

Concerning the conclusions drawn, we propose that it is necessary to further investigate into the technological skills that transcend basic technical proficiency and to consider the skills linked to autonomy development. The future of knowledge and culture can no longer be found only in books, newspapers, TV, radio, discs, CDs, or in the cinema. Instead, we can also find it in digital files thanks to our universal medium, the Internet -an endless library of available resources that leads us to an open world of possibilities. Thus, we need to combine the traditional reading culture with the current digital reading and be able to build new reading methodologies into the field of language education.

\section{References}

American Association of Colleges of Teacher Education (AACTE) and the Partnership for 21st Century Skills (P21). 21st century knowledge and skills in educator preparation. London: Pearson.

Alexander, P.A., \& Jetton, T. L. (2000). Learning from text: A multidimensional and developmental perspective. In M. L. Kamil, P. B. Mosenthal, P. D. Pearson, \& R. Barr (Eds.), Handbook of reading research, Vol.3 (pp. 285-310). Mahwah, NJ: Erlbaum. 
Anderson-Inman, L., \& Horney, M. (1997). Electronic books for secondary students. Journal of Adolescent \& Adult Literacy, 40, 486-491.

Anderson-Inman, L., Horney, M.A., Chen, D., \& Lewin, L. (1994, April). Hypertext literacy: Observations from the ElectroText project. Language Arts, 71, 37-45.

BECTA. (2008). Web 2.0 technologies for learning at KS3 and KS4: Learners' use of Web 2.0 technologies in and out of school. London: BECTA.

Benson, P. \& Chik, A. (2010). New literacies and autonomy in foreign language learning. In M-J. Luzón, M.N. Ruiz-Madrid \& M.L. Villanueva (Eds.) Digital genres, new literacies and autonomy in language learning (pp. 63-80). Newcastle-upon-Tyne: Cambridge Scholars Publishing.

Coiro, J. (2003). Reading comprehension on the Internet: Expanding our understanding of reading comprehension to encompass new literacies. The Reading Teacher, 56, 458-464.

Dooly, M. (2009). New competencies in a new era? Examining the impact of a teacher training project. Recall , 21 (3), 352-369. http://dx.doi.org/10.1017/s0958344009990085

Dooly, M. (2014). Learning to e-function in a brave new world:Language teachers' roles in educating for the future. In A. Turula \& B. Mikolajewska (Eds.) Insights into technology enhanced language pedagogy (pp. 9-249. Warsaw Studies in English Language and Literature. Vol. 18, J. Fisiak (Ed.). Bern/Vienna: Peter Lang.

Girón García, C. (2013). Learning styles and reading modes in the development of language learning autonomy through "Cybertasks". (Unpublished Thesis). Universitat Jaume I. Retrieved 3 June 2015 from http://hdl.handle.net/10803/125440

Girón-García, C., \& Ruiz-Madrid, N. (2013). Design and development of a WebQuest for the course 'English Applied Linguistics: An Introduction' (EA0914). Evaluation of its educational role in the Classroom. Valencia: Publicacions Universitat Politècnica de Valencia. 
Herrera, L. (2012). Youth and citizenship in the digital age: A view from Egypt. Harvard Educational Review , 333-352. http://dx.doi.org/10.17763/haer.82.3.88267r117u710300

Kellner, D. (2000). Critical perspectives on visual imagery in media and cyberculture. Journal of Visual Literacy, 22(1), 81-90.

Kern, R. (2000). Literacy and language teaching. Oxford: Oxford University Press.

Kress, G. R. (2003). Literacy in the new media age. London: Routledge Falmer.

Kress, G. \& van Leeuwen, T. (2001). Multimodal discourse: The modes and media of contemporary communication. London: Arnold.

Labbo, L. D., Leu Jr., D. J., Kinzer, C., Teale, W. H., Cammack, D., Kara-Souteriou, J. (2003). Teacher wisdom stories: Cautions and recommendations for using computer-related technology for literacy instruction [Electronic version]. Reading Teacher, 57 (3), 300-304.

Luzón, M. J. (2002). The spoken features of academic and professional electronic discourse. Oral Skills, Resources and Proposals for the Classroom: 147-160.

M-J. Luzón, M.N. Ruiz-Madrid \& M.L. Villanueva (Eds.) (2010). Digital genres, new literacies and autonomy in language learning. Newcastle-upon-Tyne: Cambridge Scholars Publishing.

Morgan, W. (1997). Critical literacy in the classroom. New York: Routledge.

Schmar-Dobler, E. (2003). Reading on the Internet: The link between literacy and technology. Journal of Adolescent \& Adult Literacy, 47(1): 80-85.

Sutherland-Smith, W. (2002). Weaving the literacy Web: Changes in reading from page to screen. The Reading Teacher, 55: 662669.

Tapscott, D. (1998). Growing up digital: The rise of the net generation. New York: McGraw-Hill.

Thorne, S.L., Black, R., \& Sykes, J. (2009). Second language use, socialization, and learning in internet interest communities and online gaming. Modern Language Journal, 93: 802-821. http://dx.doi.org/10.1111/j.1540-4781.2009.00974.x 
Fitzgerald, J., \& Shanahan, T. (2000). Reading and writing relations and their development. Educational Psychologist, 35(1), 39-50. http://dx.doi.org/10.1207/s15326985ep3501_5

${ }^{1} \mathrm{~A}$ WebQuest is an inquiry-oriented lesson format in which most or all the information that learners work with comes from the web. The model was first developed by Bernie Dodge in 1995 and since its inception two decades ago has become a well-known format for Internet-based pedagogical interventions.

\section{Author information:}

Carolina Girón-García is a Teaching Assistant at the Department of English Studies, Universitat Jaume I (Spain). She recently defended her doctoral dissertation entitled Learning styles and reading modes in the development of language learning autonomy through "Cybertasks", under the supervision of Dr. Ignasi Navarro i Ferrando and Dr. María Luisa Villanueva Alfonso.

Email: gironc@uji.es

To cite this article:

Girón-García, C. (2015). Literacy and technologies in EFL settings: Fostering reading comprehension on the Internet. Bellaterra Journal of Teaching \& Learning Language \& Literature, 8(2), 69-100. DOI: http://dx.doi.org/10.5565/rev/jtl3.616 